\title{
ON THE ISSUE OF THE RELATIONSHIP BETWEEN BASIC AND APPLIED KNOWLEDGE. METHODOLOGICAL ASPECT
}

\begin{abstract}
The article discusses the current methodological problems of the relationship between theoretical and applied knowledge in the context of the development of new industrial revolution technologies. In the study, it is argued that the linear-chain model of the relation of basic and applied knowledge has been replaced by the model of emergent-exponential relation, which is essential not only from the epistemological point of view but also from the point of view of substantiating the need for a new structure of the field of science and the implementation of a new policy towards it within the development of all spheres of public life.
\end{abstract}

Keywords: theoretical knowledge, basic knowledge, applied knowledge, technique, technology, linear dependence, emergency system, innovation.

Introduction

The rapid development of science and technology in recent decades and the further interpenetration of these interdependent fields have led to qualitative changes in many humanities, political, economic, social, cultural and other spheres of life that are difficult to control and exaggerated. Those changes pose such risks as to doubt the average progress of humanity, even its physical existence. The new type of coronavirus (SARS-Cov-2), which hit humanity in the first half of 2020, and scientific studies of its origin, nature and possible near and far effects are facing great difficulties, requiring both in-depth and fundamental research based on their theoretical findings to achieve experimental and practical results as soon as possible. In the current conditions, the problem of acquiring such new generalizations of theoretical and methodological nature, which will allow responding to the new challenges adequately, becomes urgent again.

From this point of view, it is imperative to observe the latest technological trends, which have become dominant during the previous decade, in the context of the rapid development of so-called modern convergent technology cluster (Nano (N), Bio (B), Info (I), Cognitive (C) technologies (NBICs), which is likely to form a somewhat new paradigm of the relationship between basic and applied knowledge.

\section{Literature and Sources Review}

In the developed countries of antiquity, the desire for new knowledge was, first and foremost, a mission to seek and find the truth. The latter was, in fact, based on the aspirations to philosophically perceive and make sense of the world and the environment. However, over time, 
along with the accumulation of scientific knowledge, especially the definition and delimitation of certain areas of the natural sciences, and finally the coordination of sciences, the goal of scientific research became the creation of new goods through the creation and development of techniques and technologies.

In the $19^{\text {th }}$ century and especially in the $20^{\text {th }}$ century, the applied function of the result of science could be said to have had a dominant significance. However, at that time, the model of scientific cognition was widely used, which was based on the fundamental (or pure) definite delimitation of the applied sciences and even the principle of opposition. However, over time, the methodological reality that the certainty or stability of any fundamental science is first and foremost conditioned by a basis for any research with applied output has become more and more visible and decisive. And, in fact, one of the main qualities of the so-called "pure science" is more and more becoming the fundamentality.

Especially during the last two decades, the discourse mentioned above on the essential generalizations about the role of science and basic knowledge in the development of society has received new manifestations. It has always been said that the philosophical approaches to the creation of science or scientific knowledge aimed at revealing the truth, to the patterns of inanimate nature (human nature), to the discovery of truth, have undergone qualitative changes. The philosophical approaches to the patterns of inanimate and living nature (human nature), that is, the creation of science or scientific knowledge to reveal the truth, their classification, have undergone constant qualitative changes. There seems to be a consensus among theorists that in the modern information society, science, or, in a broader sense, knowledge production, has entered its so-called post-non-classical science stage, where pure or fundamental science is integrated with technology.

Over the last decade, the point of view that the cognitive function of basic research seems to be qualitatively transformed into a more systematic and emergent relationship in terms of the fact that they are considered on a common platform in the field of applied science, and their links and feedback on technology seem to be prevalent among theorists studying scientific research methodology. In particular, such theoretical and methodological approaches are based on the revolutionary effects of information and telecommunications technologies, under which scientists have had the opportunity to create virtual means and tools from the point of view of obtaining more effective ways and means of practical transformation of basic knowledge (Drotianko, Abysova, Chenbai, \& Shorina, 2020, p. 14).

Theorists describing the above realities present science in an extra-subjective (transdisciplinary) context, in contrast to the previous context of interdisciplinary science in the development of science. Theorists describe such a description of modern science with the term "technology", which is preferably a transdisciplinary characteristic in the sense that science perceives and evaluates in a complex, social-technocratic context. In particular, Gilbert Hottoyz (2004), a professor at the Freedom University in Brussels, was one of the first to introduce the term "technology", explaining that the objectivity of modern science is manifested in the creation of its physical and technical efficiency. He emphasizes. "Technosciences create the realities that they themselves study" (p. 262). For his part, the French philosopher-sociologist Bruno Latour (1998) described the new relationship between 
science and society as a "space for self-regulation of human-object relations". He clarifies: "If in the past society sponsored independent science, remaining alien to the principles and methods of expressing scientific rationality, now science and what we call the society using the traditional term, is simply intertwined" (p. 209).

Porus V. (2020) views the issue of the relationship between the basic and applied components of scientific research in the context of interactions with different disciplines, considering that the dynamics of scientific cognition is a "multi-vectorial process" and is conditioned not only and not so much by the relationship of potential and internal elements of science, but by many external factors (p. 80). This means that the development of science is by its nature not only a process characterized by a linear, predictable and uniform trajectory but also a process characterized by an exponential function and, in many cases, extra-scientific and interdisciplinary interactions and decisive feedback. Some theorists ask the question much more clearly, considering that at present, the creation of theoretical knowledge is inseparable from the possibilities of its practical application. In many cases, researchers view the results of scientific research as inseparable from their social context.

In particular, according to D. Bloor (1976), the objectivity of knowledge is conditioned by its social significance (p. 156). On the other hand, another group of theorists considers the knowledge of the basic truth and the creation of knowledge as a highly individual, supersocial and supercultural phenomenon. This so-called normative approach was more emphatically expressed by E. Goldman (2003, p. 407). Nevertheless, some authors develop an intermediate or compromise point of view by not accepting the two mentioned descriptive-normative approaches. In particular, S. Fuller (2002) is convinced that the sociality of knowledge has a network structure, which ensures its stability. At the same time, within the framework of this approach, knowledge is considered as social capital, the realization of which cannot have a normal process without a social environment.

The system of modern scientific research is evaluated by theorists of the methodology of science not only and not so much from the point of view of interdisciplinarity, but the point of view of transdisciplinarity. According to $\mathrm{B}$. Nicolescu (2015), one of the main theorists of the concept of transdisciplinarity, in contrast to the interdisciplinary approach, where different levels of reality are studied by different disciplines, transdisciplinarity studies multi-level reality at the same time and combines it as a single whole (p. 63). In addition, during the cognition of reality, the opposite sides of the phenomena are not opposed but combined based on the principle of complementarity. Based on such assertions, some authors note that, especially during the technological upheavals of the last decade, the boundaries between basic scientific research and innovations are simply erased; otherwise scientific knowledge merges with the living environment of society and human society (Gibbons, Trow, Scott, \& Schwartzman, 1994).

\section{Basic Analysis}

It should be noted that any significant practical and fundamental (basic) knowledge from the point of view of the strategic development of the state and, in general, the normal and transitional evolution of mankind, should be thoroughly examined, that is, not only from the point of view of specific economic, military and social goals in terms of its profitability but also in terms 
of all the parameters of the expertise, from the point of view of long-term consequences and effects. For example, the production or sale of this or that drug by a company is certainly a business, but examining the side effects of its use and its effects is in the public interest, its long-term effects on society and the interests of its health care.

The same applies, for example, to food safety issues. In particular, the many experiments that synthesize biologically new compounds and new foods raise questions about the extent to which they are in the public interest, for example, the creation and distribution of genetically modified food. For example, in Armenia and in other developing countries nowadays, the production of vegetables, grain varieties, fruits and other foods is subject to numerous artificial interventions. Many of their varieties are the result of the development of artificial genetic compounds and scientific experiments; in particular, the main goal is to increase plant productivity, that is, business efficiency and productivity. However, the long-term effects and consequences of such new compounds on human reproductive health and their effect in terms of being carcinogenic or causing genetic abnormalities are, of course, not seriously discussed in many cases. The same applies especially to the process of import and export of food.

The above-mentioned examples show that, indeed, in the conditions of modern technological science, the processes of general-theoretical perceptions and generalizations of phenomena and reality connections are closely interconnected with technical intervention; otherwise, "the chain of basic research is inextricably linked with the material conditions of its creation" (Nordmann, 2006). However, this does not mean that such a chain connection means that basic research is pushed to the background in terms of its importance. This is not possible, at least because, from the point of view of continuous nourishment of applied knowledge, creation of new technical-technological devices and, especially, their improvement, the processes of guiding basic research and applying practical solutions based on them must not always stop. The assertions mentioned above are very relevant today, especially in the conditions of spreading the priorities of business interests, their dictation and, sometimes, their imminent threats to human health and life. It can be stated that in many cases, states either intentionally or unintentionally create and export food to other countries, which is highly questionable and dangerous in terms of its safety, food purity and usefulness. The same goes for drugs.

By and large, if we look at the root of the problem, the situation is like this: very often, the researcher works in the laboratory to get a specific applied result with certain parameters, and that work has a specific client, financier. In other words, the application of the obtained result is aimed at satisfying a specific need - food, health care, rest or anything else. Furthermore, in this case, it becomes undesirable and unnecessary in the other, derivative and related, or side effects and consequences in the client's duality (financier)-researcher (performer). Moreover, here, most likely, the parties tend to exhibit so-called opportunistic behaviour and, in fact, hide from the public the side effects of the given good, extraneous and, for the most part, dangerous consequences. And the whole contradiction here is that the rights to a given novelty (discovery, invention, another object of intellectual property, for instance, a utility model or industrial design, etc.) can be registered and protected by legal, institutional mechanisms (licensing, etc.), which 
can create an unresolved conflict of interests in the relations of public interests and specific business groups and individuals, create conflict situations, even in local, regional and global terms.

From this point of view, the dramatic and tragic developments associated with the new global acute respiratory syndrome (COVID-19) and the irreversible consequences associated with consideration of the insufficient examination, in a positive sense, vulnerable circumstances of significance and applicability of results of research conducted by a number of scientific groups and individuals in highly questionable circumstances. The same question applies to so-called environmental impact assessments when new mines are opened, or existing ones are examined. And the fact that in many cases the purely economicbusiness interest, that is, the practicality acquires a great dominance, becomes an evil on the head of this or that country, people or even humanity.

The fact that from the point of view of basic knowledge, the main criterion is science, and from the point of view of applied science, the main criterion of the result is usefulness (utilitarianism), is in fact, the main watershed of these two parts of research. From this point of view, what is happening in connection with the developments around COVID-19 is significant. It is connected with the distortions of that reality described above, while it may have had specific clients and financiers. They are specific laboratories, specific scientists or groups of them and specific groups of people who have pursued transparent business, political and, possibly, geopolitical goals.

It can be argued that the purpose of applied scientific research is not an in-depth study, the discovery of reality, but the transformation of that reality or the environment, the creation of new structures, which is innovation. The whole problem is that applied knowledge solves a problem of a specific structure and the consequences of its application have virtually no significance for its creators or clients. From this point of view, any basic technology, which, for example, causes revolutionary changes in the energy sector, was considered the best. However, as time goes on, it turns out that the already established and widespread technology has such negative consequences that neutralize or eliminate require much more energy, efforts and resources rather than the creation of the technology itself and the effect of its application. Many examples can be given from this point of view.

For example, when coal or fuel oil were replaced by nuclear power plants in the post-war period, the problem of ecologically clean, much cheaper electricity sources was considered solved. However, over time it became clear that this is not the case. Over time, nuclear power plants, working and consuming the metal resources of their reactors, become extremely dangerous to the environment and especially to humans, and large-scale resources are needed to neutralize them. This refers to the nuclear fuel it has developed, which requires plenty of resources to store and neutralize. It is true that sometimes they are used as raw materials for the production of nuclear weapons, but in the end, it also has its limits. Today humanity has created and accumulated so many nuclear weapons that are enough to destroy the planet 300 times. Moreover, those enormous arsenals of nuclear weapons today have become a severe threat not only to the countries that created those weapons but to the rest of the world.

If we look at the root of this phenomenon, the scientists, at the beginning of the creation of nuclear weapons, did not think at all that the products of their insightful thinking could eventually 
become sources of deadly weapons. For example, Albert Einstein, when he was developing his theory of relativity, did not have such aspirations at all. However, some scientists and experimenters turned Einstein's basic ideas into deadly weapons. As far back as the famous $17^{\text {th }}$-century philosopher Francis Bacon said, the progress of science is the progress of humanism in the sense that the development of technology and its useful application will help solve the social problems of society to overcome poverty (Bacon, 1620). However, the course of history has proved the opposite in many ways. In many cases, scientific and technological progress has led to terrible wars and bloody conflicts between nations.

Was it possible to predict the possibility and the prospect of misusing the application of essential knowledge through expertise? This question is not rhetorical at all. There is a lot of talks today that SARS-Cov-2 is an artificial coexistence and is ordered by military agencies, specifically by the US Department of Defense, the Pentagon. Possibly, it is true, but the whole problem is to what extent such fundamental research can be controlled by the given country and the world community as a whole.

This is a challenging issue in the sense that the delegation and application of applied knowledge, which is linked to and derived from business interests, as is often mediated by the need to increase the level of defence capacity of the country. And the creation of chemical, biological and nuclear weapons of mass destruction in specific laboratories is the result of the efforts and capabilities of specific scientists, specific engineers, specific experimenters. Their clients, of course, are the governments of the states, certain international structures and organizations.

However, the question of to what extent these applied results are examined and substan- tiated in terms of their long-term and systemic effects, exclusion of related and undesirable consequences, is a major issue. This refers to the latest developments in genetic engineering, various genetic experiments, the latest systems of artificial intelligence, the risks of new nanostructures and the creation of coexistences.

Figuratively speaking, if the products of a scientist and engineer in a particular field of science are evaluated from the point of view of political or business interests, military or any other purpose and the evaluation or expertise of their effectiveness is carried out with the help of specific functions or parameters of a particular branch of science, the general evaluation is carried out from the point of view of the achievements of science as a whole, evaluating as comprehensively and completely as possible the whole spectrum of the effects of the given invention or discovery. In other words, if the evaluation of applied knowledge is carried out from the point of view of usefulness, then the basic knowledge must be evaluated on the basis of the principle of scientificality and fundamentality.

In the context of the facts mentioned above and problems, a fundamental question arises: which of the most appropriate ways of developing science and financing its directions within a given country or on a global scale should be chosen? The question here is not only about the sources of funding for science, in terms of whether this or that scientific research should be financed mainly from state or private sources. The problem here is that this or that influential lobby group of the state bureaucracy and the society often has a great influence on the distribution of funds allocated to science. This means that political and sometimes military-political interests have a significant, often decisive influence, especially in terms of financing the basic 
sciences. And if in these conditions, the public pressure on the state policy is not balanced, then serious distortions and failures can occur in that sphere (Pestre, 2005, pp. 29-52).

Of course, the classification of scientific research into basic and applied is strictly conditional. On the one hand, it is evident that the fields of science that have visible and direct access to technologies and technical devices are obviously practical. For example, such fields are theoretical physics, theoretical chemistry or theoretical biology. Nevertheless, on the other hand, social sciences such as political science, economics, psychology, sociology or pedagogy, in fact, have no practical solutions at first sight.

However, modern humanities have such outcomes because they allow to acquire relevant technologies that have an impact on various areas of public life. For example, various political technologies, social technologies, economic policy models and systems are essentially based on fundamental developments in the sciences related to these areas, aimed at transforming the social values and value systems of human society, their groups or individuals. In modern conditions, in fact, every epoch-making basic development has a common worldview and universal impact when it becomes a factor with this or that practical outcome. These are the theoretical elaborations underlying the emergence of the socalled technologies of the 4th Industrial Revolution. The issue of the emergence of so-called NBIC technologies and their far-reaching implications is far more critical than the question of their practical application.

\section{Conclusion}

It can be said that the division of basic and applied segments of the field of scientific rese- arch and their consideration and the opposition within a direct, linear relationship is one of the methodological foundations of the traditional paradigm of the philosophy of science, that is, mainstream. In fact, for the last two centuries, this thesis has been dominant in the fields of science and research, especially during the last two decades, the rapid development of research and technologies, spatial and in-depth processes of digitalization and means of communication have created an entirely new situation, including in terms of methodological reinterpretation of these processes. However, especially during the last two decades, the rapid development of research and technologies, spatial and in-depth processes of digitalization and means of communication have created a completely new situation, including from the point of view of methodological reinterpretation of these processes.

The development of science and technology in modern conditions and their relations with many other systems of society are undergoing radical, qualitative changes. It becomes evident that modern science and technologies and innovations are integrated into an emerging system consisted of interconnected and complementary elements. In our opinion, the main philosophical perception and assessment of new developments, in terms of the methodology, are that the fields of basic and applied research are being integrated into the whole of such an emerging system.

On the other hand, the development of science as a combination of coordinated and complementary vectors of these two interrelated elements is related to the so-called demand-creating effects of more extensive public life subsystems (military, political, economic, educational, health, social, etc.). The increase in the price of scientific research, the complication, the expansion of the system, and the experimental base force 
more and more extensive resources to be allocated to science development. All this forces the political elites to show more responsible, more sober behaviour in making political or administrative decisions on financing science or technology directions.

\section{Acknowledgements}

This work was supported by the RA MESCS State Committee of Science, in the frames of the research project № 18T-5B152.

\section{References}

Bacon, F. (1620). The New Organon: Or True Directions Concerning the Interpretation of Nature. Retrieved from https://www.earlymoderntexts.com/assets/pdfs bacon1620.pdf.

Bloor, D. (1976). Knowledge and Social Imagery. London: Routledge and Kegan Paul.

Drotianko, L., Abysova, M., Chenbai, N., \& Shorina, T. (2020). Post-non-Classical Science in the Age of Informatization of Society: Functional Aspect. E3S Web of Conferences 157, 04003. Retrieved from https://www.e3s-conferences.org/articles/e3sconf/pdf/2020/17/e3 sconf ktti2020 04003.pdf.

Fuller, S. (2002). Not the Best of All Possible Critiques. Social Epistemology, 16(2), 149-155. doi:10.1080/02691720210150789.

Gibbons, M., Trow, M., Scott, P., \& Schwartzman S. (1994). The New Production of Knowledge: The Dynamics of Science and Research in Contemporary Societies. London: Sage Publications. doi:10.2307/2076669.

Goldman, A. I. (2003). Knowledge in Social World. Oxford-New York: Oxford University Press.

Hottoyz, G. (2004). Techno-Sciences and Ethics. In E. Agazzi, Right, Wrong and Science: The Ethical Dimensions of the Techno-Scientific Enterprise (C. Dilworth, Ed.). Poznan Studies in the Philosophy of Science and Humanities (Vol. 81). (Monographs-in-debate) Amsterdam-N.Y.

Latour, B. (1998). From the World of Science to That of Research? Science magazine, 280(5361), 208-209. https://doi.org/10.1126/science.280.5361.208.

Nicolescu, B. (2015). The Hidden Third and the Multiple Splendor of Being. In V. Bazhanov \& R. V. Sholts (Eds.), Transdistsiplinarnost' $v$ filosofii i nauke: podkhody, problemy, perspektivy (Transdisciplinarity in Philosophy and Science: Approaches, Problems, Perspectives, in Russian) (pp.62-79). Moscow: Navigator.

Nordmann, A. (2006). Collapse of Distance: Epistemic Strategies of Science and Technoscience. Danish Yearbook of Philosophy, 41, 7-34. Retrieved from https://tuprints.ulb.tu-darmstadt.de/6876/1/ALFRED NORDMANN COLLAPSE OF DISTANCE.pdf.

Pestre, D. (2005). The Technoscience between Markets, Social Worries and the Political: How to Imagine a Better Future? In H. Nowotny, D. Pestre, E. SchmidtAußmann, H. Schulze-Fielitz, \& H.-H. Trute (Eds.), The Public Nature of Science under Assault. Politics, Markets, Science and the Law (pp. 29-52). Ber- 
On the Issue of the Relationship Between Basic and Applied Knowledge.

lin, Heidelberg: Springer.

Porus, V. (2018). Contextualism in Philosophy of Science. Epistemology \& Philosophy of Science, 55(2), 75-93. doi:10.5840/eps201855230. 